\title{
Neuronal Acetylcholine Receptors with $\alpha 7$ Subunits Are Concentrated on Somatic Spines for Synaptic Signaling in Embryonic Chick Ciliary Ganglia
}

\author{
Richard D. Shoop, ${ }^{1}$ Maryann E. Martone,, ${ }^{2}$ Naoko Yamada,, ${ }^{2}$ Mark H. Ellisman, ${ }^{2}$ and Darwin K. Berg' \\ ${ }^{1}$ Department of Biology and the ${ }^{2}$ National Center for Microscopy and Imaging Research, University of California, San \\ Diego, La Jolla, California 92093-0357
}

Nicotinic acetylcholine receptors containing $\alpha 7$ subunits are widely distributed in the vertebrate nervous system. In the chick ciliary ganglion such receptors generate large synaptic currents but appear to be excluded from postsynaptic densities on the cells. We show here that $\alpha 7$-containing receptors are concentrated on somatic spines in close proximity to putative sites of presynaptic transmitter release. Intermediate voltage electron microscopy on thick sections, together with tomographic reconstruction, permitted three-dimensional analysis of fingerlike projections emanating from cell bodies. The projections were identified as spines based on their morphology, cytoskeletal content, and proximity to presynaptic elements. Both in situ and after ganglionic dissociation, the spines were grouped on the cell surface and tightly folded into mats. Immunogold labeling of receptors containing $\alpha 7$ subunits showed them to be preferentially concentrated on the somatic spines. Postsynaptic densities were present in vivo both on the soma near spines and occasionally on the spines themselves. Synaptic vesiclefilled projections from the presynaptic calyx were interdigitated among the spines. Moreover, the synaptic vesicles often abutted the membrane and sometimes included $\Omega$ profiles as if caught in an exocytotic event, even when no postsynaptic densities were juxtaposed on the spine. The results suggest several mechanisms for delivering transmitter to $\alpha 7$-containing receptors, and they support new ideas about synaptic signaling via spines. They also indicate that neurons must have specific mechanisms for targeting $\alpha 7$-containing receptors to desired locations.

Key words: nicotinic; acetylcholine; $\alpha 7$; ciliary ganglion; spines; receptors; neuronal; cholinergic; synaptic; calyx; presynaptic; tomography; immunogold; confocal; electron microscopy
Nicotinic acetylcholine receptors (AChRs) are widely expressed in the vertebrate nervous system where they function as cationselective ligand-gated ion channels. One of the most abundant is a species containing $\alpha 7$ subunits ( $\alpha 7$-AChRs) that has a high relative permeability to calcium and binds $\alpha$-bungarotoxin $(\alpha$ Bgt) with high affinity (Couturier et al., 1990; Schoepfer et al., 1990; Anand et al., 1993; Bertrand et al., 1993; Seguela et al., 1993; Conroy and Berg, 1998). Increasing evidence indicates that $\alpha 7$-AChRs can act presynaptically to modulate neurotransmitter release (McGehee et al., 1995; Gray et al., 1996; Coggan et al., 1997; Guo et al., 1998; Li et al., 1998).

In the chick ciliary ganglion, $\alpha 7$-AChRs play a prominent role postsynaptically. The ganglion contains ciliary neurons innervating striated muscle in the iris and ciliary body and choroid neurons innervating smooth muscle in the choroid layer (Dryer, 1994). Ciliary neurons become engulfed by large presynaptic calyces early in development and express high levels of $\alpha 7$ AChRs. The receptors generate substantial synaptic currents, representing $>90 \%$ of a $5 \mathrm{nA}$ whole-cell response in situ (Zhang et al., 1996; Ullian et al., 1997). Although the magnitude of the current is not incompatible with the number of $\alpha 7$-AChRs

Received July 15, 1998; revised Oct. 14, 1998; accepted Oct. 23, 1998.

This research was supported by National Institutes of Health Grants NS 12601 and 35469 and Tobacco-Related Disease Research Program Grant RT65-0050 to D.K.B. and by the National Institutes of Health Grant RR04050 to M.H.E.

Correspondence should be addressed to Dr. Darwin K. Berg, Department of Biology, 0357, University of California, San Diego, 9500 Gilman Drive, La Jolla, CA 92093-0357.

Copyright (ㄷ) 1998 Society for Neuroscience $\quad 0270-6474 / 98 / 190692-13 \$ 05.00 / 0$ present $\left[\geq 10^{6} /\right.$ neuron (Chiappinelli and Giacobini, 1978; Smith et al., 1983)], the synaptic response is a surprise given the location of the receptors. Electron microscopic analysis suggests that $\alpha 7$ AChRs are absent from postsynaptic densities (PSDs) on the neurons (Jacob and Berg, 1983; Loring et al., 1985) that instead contain a different species of AChR (Jacob et al., 1984; Loring and Zigmond, 1987). This latter species ( $\alpha 3 *$-AChRs) is composed of $\alpha 3, \beta 4, \alpha 5$, and occasionally $\beta 2$ subunits and binds monoclonal antibody mAb 35 (Vernallis et al., 1993; Conroy and Berg, 1995). Despite their preferred location, $\alpha 3^{*}$-AChRs generate only a minor portion of the synaptic current in many ciliary neurons (Zhang et al., 1996; Ullian et al., 1997).

Confocal fluorescence microscopy with derivatized $\alpha$-Bgt suggested that $\alpha 7$-AChRs are concentrated in perisynaptic clusters on ciliary ganglion neurons (Wilson Horch and Sargent, 1995). Electron microscopic analysis using horseradish peroxidase (HRP)-conjugated $\alpha$-Bgt indicated preferential labeling of extrasynaptic membrane among finger-like processes emanating from the neurons (Jacob and Berg, 1983). The processes have usually been referred to as pseudodendrites (Szentagothai, 1964; Hess, 1965; Landmesser and Pilar, 1972). A subsequent electron microscopic study using ${ }^{125} \mathrm{I}-\alpha$-Bgt and autoradiography supported the conclusion that $\alpha 7$-AChRs are distributed throughout extrasynaptic membrane but left unanswered the question as to whether the receptors are preferentially concentrated on the processes (Loring et al., 1985).

We have used immunogold labeling, together with intermediate voltage electron microscopy (IVEM) and tomographic analysis, to examine the distribution of $\alpha 7$-AChRs on chick ciliary 

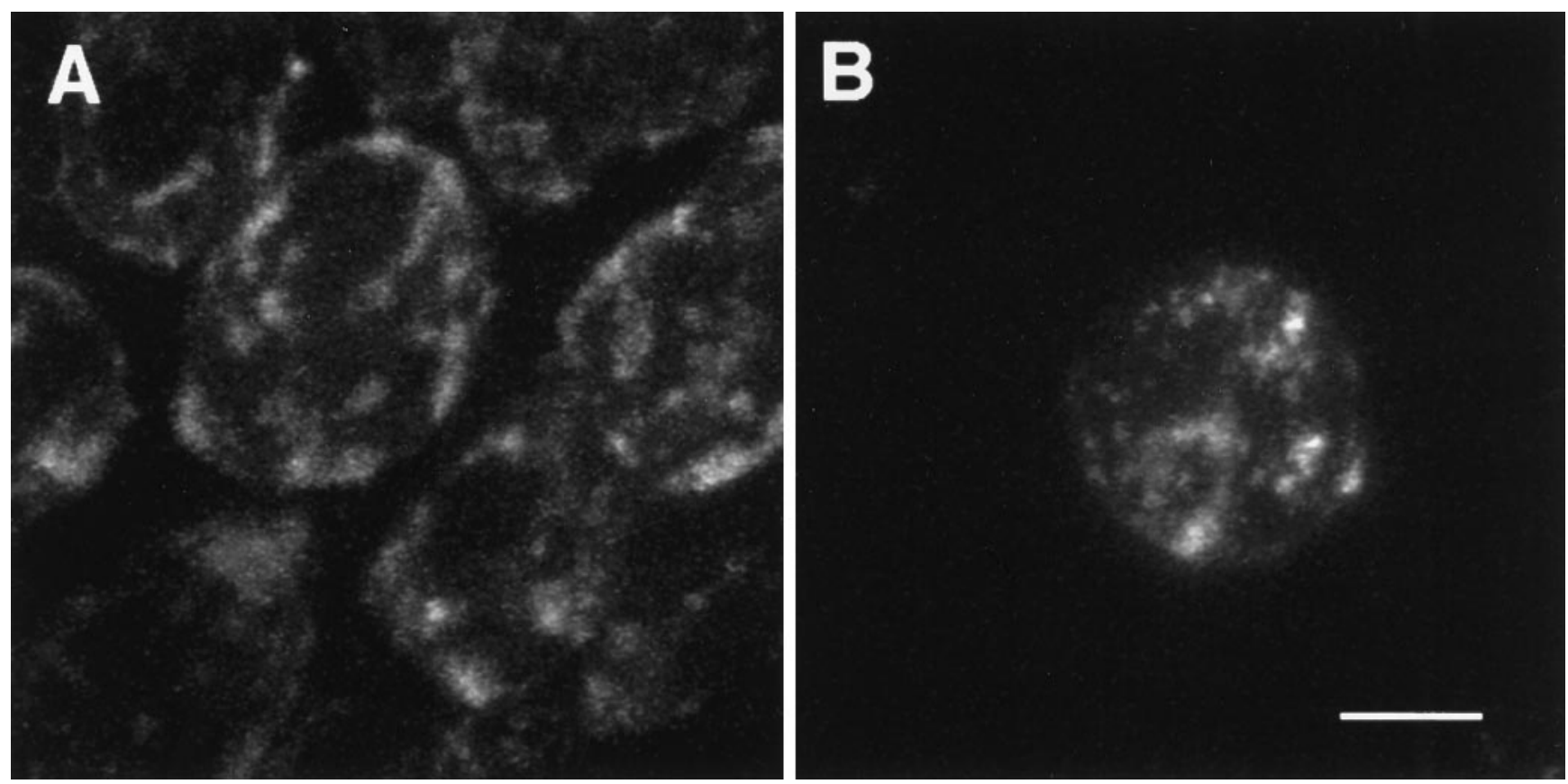

Figure 1. Confocal immunofluorescence comparing the distribution of $\alpha 7$-AChRs on ciliary ganglion neurons in situ $(A)$ and in dissociated cell culture $(B)$. Labeling of $\alpha 7$-AChRs was obtained with biotinylated $\alpha$-Bgt followed by Cy3-conjugated streptavidin. Large receptor clusters $1-4 \mu \mathrm{m}$ in diameter were apparent in both kinds of preparations. Scale bar, $10 \mu \mathrm{m}$.

neurons late in embryogenesis. We find the receptors are concentrated on somatic spines in close proximity to multiple sites of presumed transmitter release. The receptor distribution and spine configuration suggest a model for chemical transmission through ciliary neurons that makes economical use of transmitter while supporting high-frequency signaling and possible sequestration of calcium entering through activated $\alpha 7$-AChRs.

\section{MATERIALS AND METHODS}

Sample preparation. Ciliary ganglia were dissected from embryonic day 15 (E15) chicks and either labeled and processed directly for confocal and electron microscopy or dissociated into a cell suspension and allowed to settle on coverslips as described previously (Zhang et al., 1994) before labeling and processing. After labeling, samples were prepared for fluorescence visualization by fixation in $4 \%$ paraformaldehyde in phosphate buffer, $\mathrm{pH}$ 7.4; samples prepared for electron microscopy (EM) were fixed in $2 \%$ paraformaldehyde plus $2 \%$ glutaraldehyde in cacodylate buffer, $\mathrm{pH} 7.4$.

Immunolabeling of cultured cells and tissue sections. After allowing 20 min for dissociated cells to attach to the culture substratum, we incubated the cultures for $1 \mathrm{hr}$ at $4^{\circ} \mathrm{C}$ in $10 \mathrm{~mm}$ HEPES, pH 7.4, containing either biotinylated $\alpha$-Bgt (1:500 dilution; Molecular Probes, Eugene OR) to label $\alpha$-AChRs or the rat monoclonal antibody mAb 35 (1:1000 dilution) to label $\alpha 3^{*}$-AChRs (Wilson Horch and Sargent, 1995; Conroy and Berg, 1998). Cultures were then rinsed five times with 10 mM HEPES, pH 7.4, followed by $30 \mathrm{~min}$ of fixation and rinsing for $20 \mathrm{~min}$ in $0.01 \mathrm{M}$ sodium phosphate, $\mathrm{pH} 7.5$, containing $0.15 \mathrm{M} \mathrm{NaCl}$ (PBS). To detect bound biotinylated $\alpha$-Bgt with immunofluorescence, we incubated labeled cultures $45 \mathrm{~min}$ in either Cy3- or FITC-conjugated streptavidin (1:1000 in PBS; The Jackson Laboratory, Bar Harbor, ME). To detect bound mAb 35 with immunofluorescence, we incubated cultures $45 \mathrm{~min}$ in a 1:200 dilution of Cy3-conjugated donkey anti-rat antibody (The Jackson Laboratory). For immunogold labeling, cultures were first incubated $45 \mathrm{~min}$ in PBS with a 1:200 dilution of mouse anti-biotin (The Jackson Laboratory), rinsed five times in PBS, and then incubated 45 min with donkey anti-mouse antibody conjugated to $10 \mathrm{~nm}$ immunogold (1:50 dilution; Amersham, Arlington Heights, IL) in PBS with 5\% (v/v) normal donkey serum. Alternatively, neurons labeled with HRP reaction product were incubated with HRP conjugated to streptavidin (or to donkey anti-rat antibody in the case of $\mathrm{mAb} 35$ ) for $45 \mathrm{~min}$, rinsed five times in PBS, and then reacted for $5 \mathrm{~min}$ using a peroxidase-labeling kit (Molecular Probes). Nonspecific (background) labeling with biotinylated $\alpha$-Bgt was assessed by incubating the neurons $20 \mathrm{~min}$ with $100 \mathrm{nM} \alpha$-Bgt before the incubation with biotinylated toxin and then processing as normal. Tissue sections were labeled for immunofluorescent detection of $\alpha 7$-AChRs as described above, using slightly longer incubation times and approximately twice as many rinses between steps. In some experiments, $\alpha 7$ AChRs were labeled with indirect immunofluorescence by fixing the cells as described above, permeabilizing with $0.1 \%$ (w/v) Triton X-100 in PBS, and then labeling with anti- $\alpha 7-\mathrm{AChR}$ antibodies (Santa Cruz Biotechnology, Santa Cruz, CA).

Phalloidin labeling was performed on neurons in culture immediately after they had been labeled for $\alpha 7$-AChRs as described above. Cells were permeabilized in PBS with $5 \%(\mathrm{v} / \mathrm{v})$ normal donkey serum and $0.1 \%$ (w/v) Triton X-100 for $20 \mathrm{~min}$ and then were incubated for $45 \mathrm{~min}$ in a 1:1000 dilution of rhodamine-conjugated phalloidin (Molecular Probes).

Confocal microscopy. Fluorescently labeled material was visualized with a Noran Instruments Odyssey (Middleton, WI) confocal microscope using a $63 \times, 1.4$ numerical aperture objective lens. Approximately 60 optical sections were taken through each sample, recorded digitally, and assembled to achieve the final volume. National Institutes of Health Image was used to analyze the confocal images.

Electron microscopy. Material for EM was rinsed in $0.1 \mathrm{M}$ sodium cacodylate buffer several times and treated for 30 min with $2 \%$ osmium tetroxide in $0.1 \mathrm{~m}$ sodium cacodylate. Samples were then counterstained with uranyl acetate (except for those containing HRP-reacted material), dehydrated in an ethanol series, and infiltrated with Durcupan ACM resin. After polymerization for $24 \mathrm{hr}$ at $60^{\circ} \mathrm{C}$, the material was sectioned into either $80 \mathrm{~nm}$ (thin-sectioned material) or 1-2 $\mu \mathrm{m}$ (thick-sectioned material).

Thin-sectioned material was examined using a JEOL 100CX electron microscope. Thick-sectioned material was examined with a JEOL 4000EX microscope, operating at $400 \mathrm{keV}$. Volume content of the thick sections was revealed by tomographic reconstruction. The $1-2-\mu \mathrm{m}$-thick sections were tilted through $120^{\circ}$ of rotation, and electron micrographs were taken at increments of $2^{\circ}$. These 61 tilt angles were then digitized, aligned, and back projected to generate the volume information using procedures described by Perkins et al. (1997). Manual tracing from the computer-generated slices using Xvoxtrace software (developed by S. Lamont, National Center for Microscopy and Imaging Research) was used to delineate the plasma membrane, spine membrane position and 


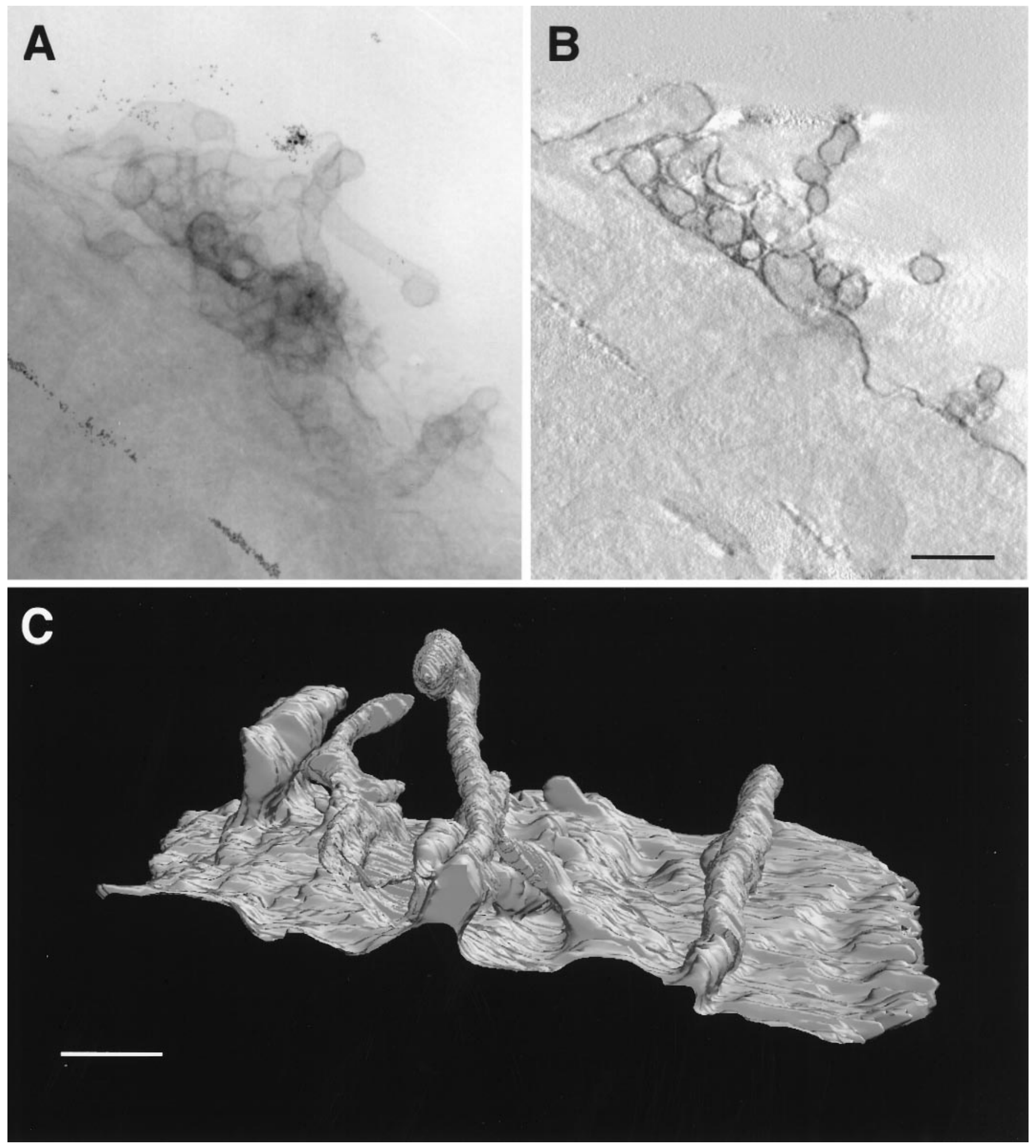

Figure 2. IVEM tomographic reconstruction of the ciliary ganglion neuron surface showing spine-like structures matted against the cell soma. Dissociated cells stained with biotinylated $\alpha$-Bgt followed by HRP-conjugated streptavidin were thick-sectioned and examined by IVEM at multiple tilt angles. $A$, Electron micrograph of 1- $\mu \mathrm{m}$-thick section showing HRP labeling of a surface region containing a tangle of processes difficult to follow. Black dots at the top and bottom left are $20 \mathrm{~nm}$ gold fiducial markers. $B$, One of many computer-generated slices through the tomographic volume showing the plasma membrane surface clearly resolved in the labeled region. $C$, A three-dimensional reconstruction of the surface plasmalemma illustrating the dense mat of spine-like projections emanating from the cell body. Scale bars, $500 \mathrm{~nm}$. 

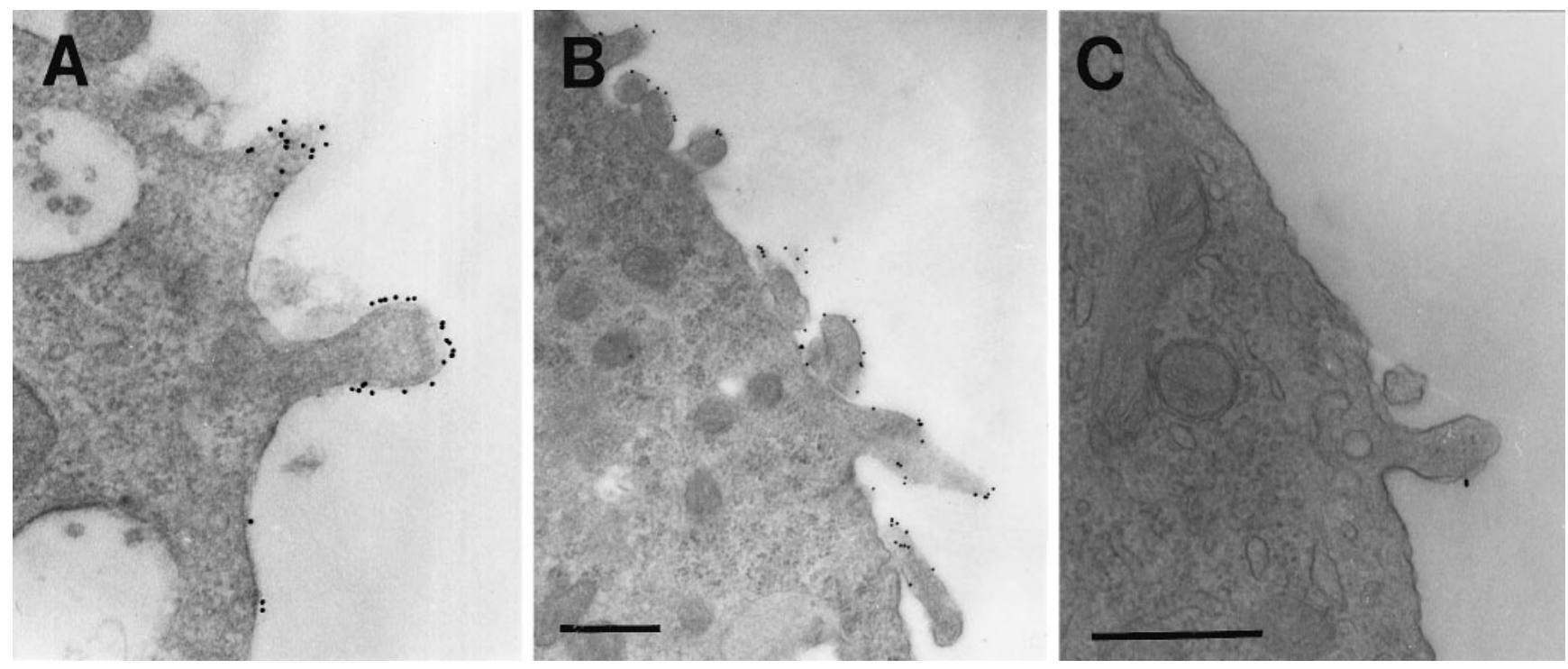

Figure 3. Conventional electron micrographs of thin sections showing immunogold labeling of $\alpha 7$-AChRs on dissociated ciliary ganglion neurons. $A$, $B$, Examples of spine-like structures with immunogold labeling achieved by incubating cells with biotinylated $\alpha$-Bgt followed by anti-biotin antibodies and gold-conjugated secondary antibodies. $C$, Control section showing minimal nonspecific immunogold labeling on a neuron surface after the cells were incubated with excess $\alpha$-Bgt before biotinylated $\alpha$-Bgt in the labeling procedure. Scale bars: $A, C, 500 \mathrm{~nm} ; B, 500 \mathrm{~nm}$.

label, and calyx structures. This information was used to construct three-dimensional computer graphic representations using the Synu software package (Hessler et al., 1992). Colors were chosen manually. Gold particles were represented one-to-one by gold spheres in the tomogram.

The number of immunogold particles per unit membrane length was estimated from electron micrographs of thin-sectioned dissociated neurons labeled with biotinylated $\alpha$-Bgt. Neuronal membrane was divided into two classes: "spiny" and "nonspiny" membrane. Spiny membrane for purposes of gold particle counts was defined as that representing an extension of at least one putative spine width (usually $0.1-0.2 \mu \mathrm{m}$ ) from the cell body and not abutting other structures that would limit access of the immunogold label. Nonspiny membrane was that clearly representing soma surface and did not include distortions or bumps that might have represented the base of a transected spine. The total number of gold particles along each type of membrane sample was summed and divided by the total length of membrane observed. Membrane length was measured using Analyze software (Mayo Clinic Foundation, Rochester, $\mathrm{MN}$ ). No attempt was made to calibrate the numerical relationship between gold particles bound and $\alpha 7$-AChRs present because the measured values for gold particle density were in all cases used only for comparative purposes, i.e., comparing the relative densities of $\alpha 7$-AChRs on spiny versus nonspiny membrane.

Calculations. The proportion of the cell surface devoted to $\alpha 7$-AChR clusters was measured from confocal micrographs of cells fluorescently labeled with biotinylated $\alpha$-Bgt and Cy3-streptavidin. The threshold for detection in these measurements was adjusted to reveal only the brightest clusters, thereby ensuring a conservative estimate of the proportion of the surface occupied by them. The extent of folding or packing of the plasmalemma in a spine clump was estimated for thin-section electron micrographs of intact ganglia. The total lineal membrane measured throughout complete spiny regions was divided by that measured for equivalent (degrees of arc) regions of nonspiny (smooth soma) membrane. This value for the relative enrichment of plasma membrane in spiny regions was then multiplied by the total area of such regions calculated above to obtain a value for the relative proportion of the total cell surface contributed by spine plasma membrane. This calculation assumes that the brightest $\alpha 7$-AChR clusters detected by immunofluorescence are coextensive with spiny regions, consistent with the immunogold labeling results reported below.

The space constant $\lambda$ was estimated for spine-like projections according to the formula: $\lambda=\left[a R_{m} / 2 R_{i}\right]^{1 / 2}$, where $a$ is the spine diameter, $R_{m}$ is the specific resistance of the spine membrane, and $R_{i}$ is the resistance of the spine interior. $R_{m}$ and $R_{i}$ were taken to be $10^{4} \Omega \mathrm{cm}^{2}$ and $10^{2} \Omega \mathrm{cm}$, respectively, the values found for mammalian cardiac neurons (Plonsey and Barr, 1989).
Materials. White Leghorn chick embryos were obtained locally and maintained at $37^{\circ} \mathrm{C}$ in a humidified incubator. $\alpha$-Bgt was purchased from Biotoxins (St. Cloud, FL). All other reagents were purchased from Sigma (St. Louis, MO) unless otherwise indicated.

\section{RESULTS}

\section{Clusters of $\alpha 7-A C h R s$ on dissociated neurons}

$\alpha$-Bgt was used as a probe for $\alpha 7$-AChRs on chick ciliary ganglion neurons because it binds with high affinity to receptors containing $\alpha 7$ subunits (Schoepfer et al., 1990) and the receptors account for the vast majority of $\alpha$-Bgt binding in the ganglion (Vernallis et al., 1993). The only other identified neuronal AChR subunit recognized by $\alpha$-Bgt in chick is $\alpha 8$, but the $\alpha 8$ gene is not expressed in the ganglion (Corriveau and Berg, 1993). Confocal fluorescence microscopy of E15 chick ciliary ganglia labeled with biotinylated $\alpha$-Bgt followed by Cy3-streptavidin shows that $\alpha 7$-AChRs are distributed in large clusters on many of the neurons (Fig. 1A). Such clusters have been described previously as perisynaptic in location because of their proximity to but nonoverlap with presynaptic sites of transmitter release assessed immunocytochemically (Wilson Horch and Sargent, 1995).

Freshly dissociated E15 ciliary ganglion neurons display similar patterns of $\alpha 7$-AChR clusters (Fig. $1 B$ ). The clusters were most prominent and distinct on the larger cells that comprised a little over one-half of the dissociated population. The smaller cells also showed nonuniform distributions of $\alpha 7$-AChRs, but the receptor clusters were less pronounced. Similar patterns of immunofluorescent staining were obtained when the cells were fixed, permeabilized, and labeled with an anti- $\alpha 7$ antibody followed by Cy3labeled secondary antibody (data not shown). Measuring the size of the larger cells with prominent clusters yielded a value of $21.2 \pm 0.4 \mu \mathrm{m}$ (mean $\pm \mathrm{SEM} ; n=29$ neurons) for their mean cell diameter. This value is midway between that reported for E14 and that for $1 \mathrm{~d}$ after-hatching ciliary neurons in vivo and threefold larger than that reported for E14 choroid neurons in vivo (Pilar and Tuttle, 1982). Accordingly, the large dissociated cell population probably contained mostly ciliary neurons and was 

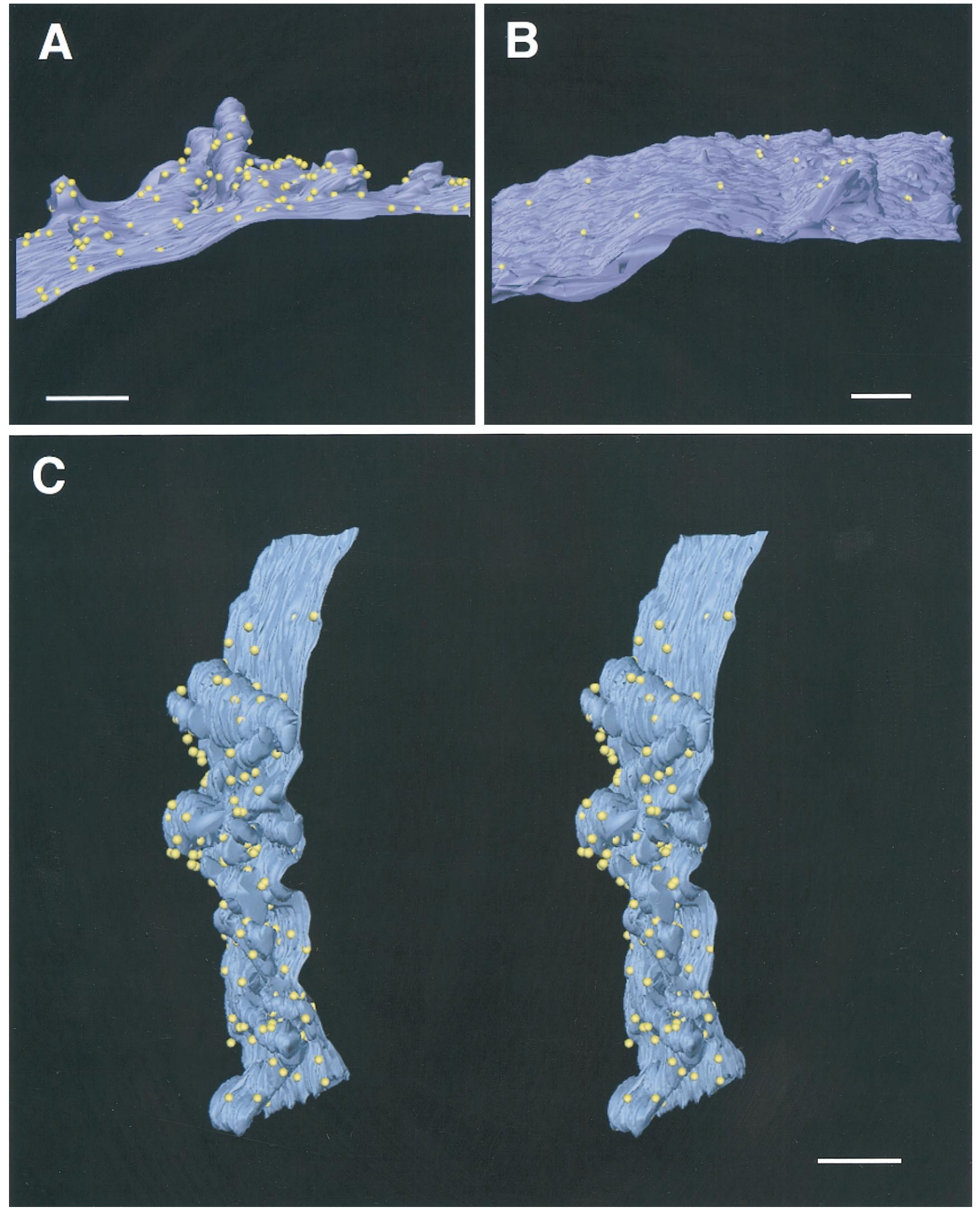

Figure 4. Three-dimensional pattern of $\alpha 7$-AChR immunogold labeling (yellow spheres) on ciliary ganglion neurons viewed with IVEM and tomographic reconstruction. $A, \mathrm{~A}$ three-dimensional reconstructed view of a patch of membrane-containing matted spines. The spines are heavily labeled with gold particles associated with $\alpha 7$-AChRs after immunogold labeling as described in Figure 3. $B$, Background levels of immunogold particles on a neuron surface prepared for nonspecific labeling as described in Figure 3. $C$, A stereo pair offering a three-dimensional view of another reconstruction of folded spines containing immunogold-labeled $\alpha 7$-AChRs. Scale bars, $500 \mathrm{~nm}$. 


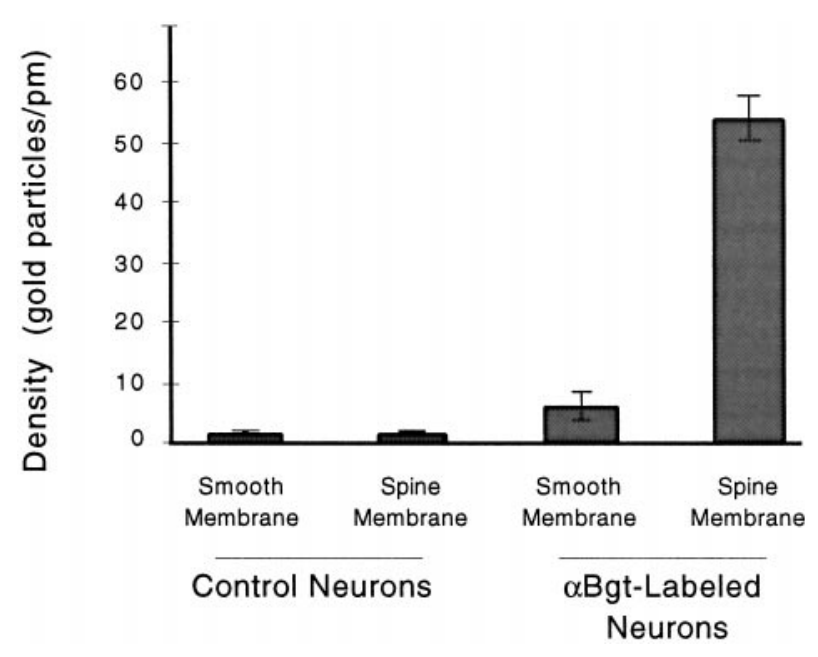

Figure 5. Relative levels of $\alpha 7$-AChRs on spine-like projections and nonspiny soma surfaces. The density of gold particles on spine-like versus nonspiny membrane segments was determined from conventional EM of thin sections after immunogold labeling for $\alpha 7$-AChRs as shown in Figure 3. Nonspiny membrane was defined as those segments having a smooth contour continuous with the cell surface and free of bumps and irregularities; spine-like membrane was defined as that involving an extension of at least one putative spine width (usually $0.1-0.2 \mu \mathrm{m}$ ) from the cell body with no abutting structures that would limit access of the immunogold label. Specific labeling of $\alpha 7$-AChRs ( $\alpha$-Bgt-labeled neurons) and nonspecific labeling (control neurons) were generated as described in Figure 3. The values shown represent the mean \pm SEM of counts on a total of 31.4 lineal $\mu \mathrm{m}$ of nonspiny membrane from 17 neurons and 26.3 lineal $\mu \mathrm{m}$ of spine-like membrane from 17 neurons (23 spines).

selected for subsequent analysis. The smaller cells seemed likely to include many choroid neurons; they were not characterized further here.

E15 ganglia were chosen for these experiments because it is a time at which many of the major developmental events have occurred on ciliary neurons; all have become innervated, preganglionic calyces have formed, naturally occurring cell death is complete, and the postganglionic target has been contacted (Dryer, 1994). Also, preliminary experiments showed that by E15 the receptor clusters were well formed and comparable with those reported in vivo for older ganglia (Wilson Horch and Sargent, 1995).

\section{Localization of $\boldsymbol{\alpha} 7-\mathrm{AChRs}$ on spine-like structures}

To examine the fine structure of $\alpha 7$-AChR clusters, we labeled freshly dissociated E15 neurons with biotinylated $\alpha$-Bgt followed by HRP-conjugated streptavidin and prepared these neurons for EM. Dissociated neurons were chosen in this case because they offered a relatively simple cellular environment and more reliable access for receptor labeling. Thick sections were examined by IVEM and were used to generate tomographic reconstructions of the HRP-labeled membrane areas. Tomographic analysis was used because it enables quantitative three-dimensional examination of fine structure within the relevant domains and thereby facilitates accurate representation of complex structures.

HRP reaction product in the thick sections was primarily associated with cell surface regions having complex membrane folds (Fig. 2A). Tomographic analysis of the thick sections was achieved by taking multiple images by IVEM at different tilt angles through the section and assembling the images into a composite three-dimensional structure (Soto et al., 1994; Perkins et al., 1997). A single reconstructed cross section generated by back projection illustrated the complexity of such labeled regions (Fig. 2B). Complete three-dimensional images indicated that the regions were composed of dense clusters or clumps of small finger-like projections emanating from the cell body and were heavily labeled with HRP reaction product. Individual projections within the clumps had the approximate dimensions of somatic spines (see below) and were usually folded back along the cell surface to form compact mats (Fig. 2C). The labeled mats ranged in size from 1 to $4 \mu \mathrm{m}$ in diameter and closely approximated both in size and number the clusters of $\alpha 7$-AChRs identified previously on ciliary ganglion neurons with confocal microscopy. No HRP reaction product was detectable on smooth soma membrane.

To determine whether $\alpha 7$-AChRs are concentrated on the spine-like structures, we subjected freshly dissociated neurons to immunogold labeling. Analysis of thin sections with conventional EM indicated prominent gold labeling of presumptive spines (Fig. $3 A, B)$. The extent of labeling varied along and among the spinelike structures, but it was very rare to find a putative spine completely lacking label. Relatively little specific labeling was found on nonspiny regions of the soma. In both cases the labeling was specific as judged by the basal levels found on cells coincubated with excess $\alpha$-Bgt to block binding of the biotinylated toxin (Fig. 3C).

Tomographic reconstruction of images collected by IVEM from immunogold-labeled thick sections confirmed the preferential association of gold particles with membrane domains rich in the folded spine-like structures (Fig. 4A). Adjacent nonspiny membrane on the same cell had lower levels of labeling. Again, the labeling was judged specific because it could be blocked by competition with unlabeled $\alpha$-Bgt during the initial binding reaction (Fig. $4 B$ ). Stereoscopic images of labeled regions containing the spine-like structures provided clear three-dimensional views of the configuration (Fig. 4C).

Immunogold-labeled thin-section images were used to quantify the number of gold particles per unit length of membrane. For purposes of quantification, nonspiny soma membrane was considered to be those regions having a consistently smooth contour defining the circumference of the cell with no deformations or irregularities. Spine-like membrane was taken to be that extending from the cell body by at least one width equivalent of the projection itself and having no abutting structures that might have impeded access of the immunogold label. The specific labeling associated with putative spines calculated in this way was an order of magnitude greater in density than that associated with smooth soma (nonspiny) membrane and was 35-40 times greater than the level of background labeling found on either type of membrane (Fig. 5). The results indicate a clear targeting of $\alpha 7$-AChRs specifically to the presumptive spines.

\section{Features of somatic spines}

By several criteria the finger-like projections appeared to represent somatic spines. Sometimes individual projections stretched out from the cell body, extending through the full thickness of the 1-2 $\mu \mathrm{m}$ section. Inspection of numerous examples of both folded and extended projections indicated they were approximately cylindrical in shape with diameters that varied from 0.1 to $0.5 \mu \mathrm{m}$ and with lengths ranging up to $4 \mu \mathrm{m}$. Inspection of thin sections by conventional EM failed to reveal microtubules and instead sometimes showed internal membrane structures with the shape and size expected for endoplasmic reticulum. Double labeling with biotinylated $\alpha$-Bgt and phalloidin followed by confocal flu- 

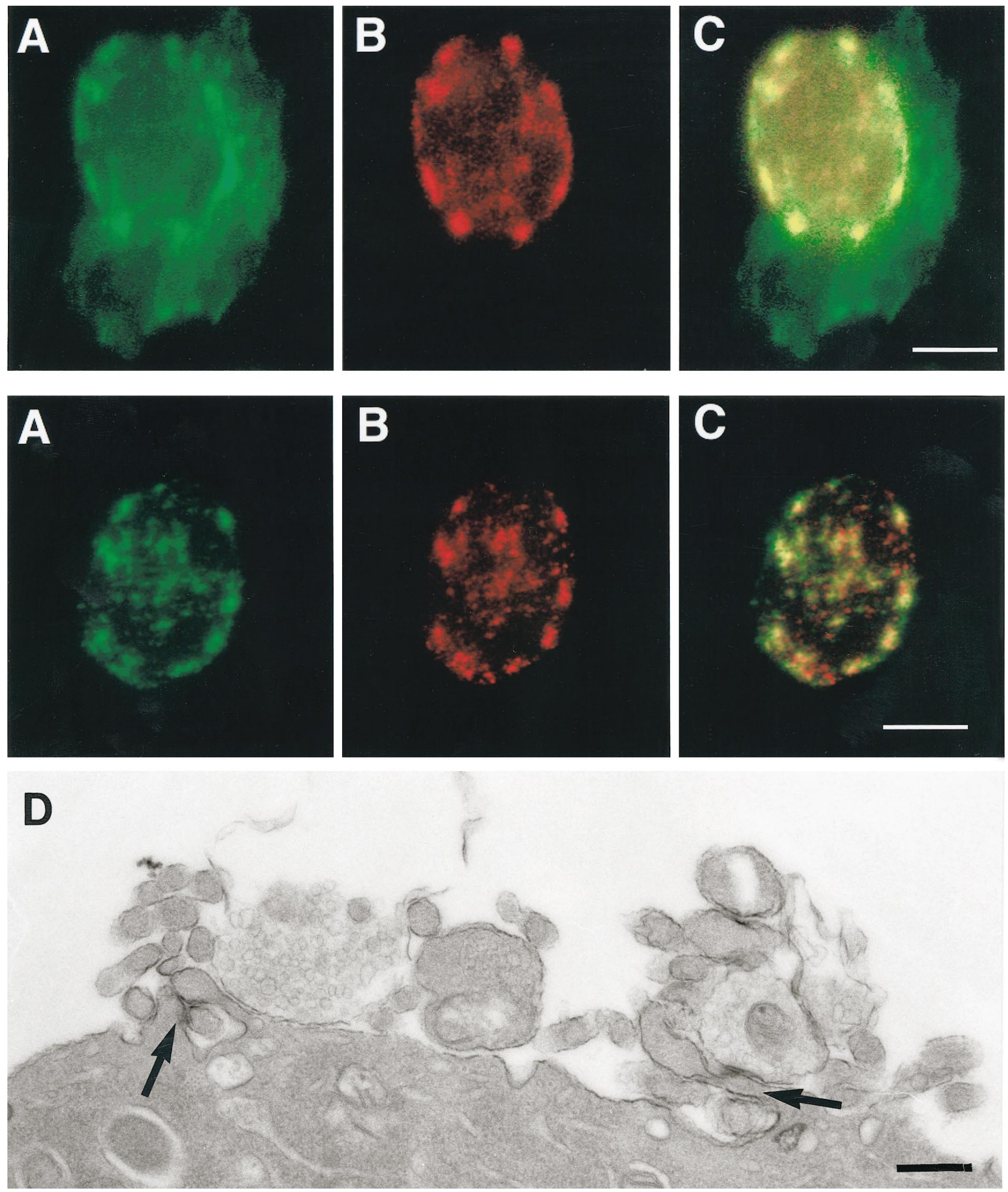

Figure 6. Confocal double-label micrographs showing codistribution of actin filament bundles and $\alpha 7$-AChRs on neurons. $A$, Phalloidin staining ( $g r e e n$ ) of a dissociated E15 ciliary ganglion neuron to detect bundled actin in spines. $B$, Same neuron stained with biotinylated $\alpha$-Bgt followed by Cy3-streptavidin (red) to visualize $\alpha 7$-AChR clusters. $C$, Overlay of phalloidin and $\alpha$-Bgt labeling showing extensive overlap (yellow). Membrane ruffles that extended from the bottom and right sides of the cell, presumably serving to anchor the cell to the substratum, contained actin bundles without codistributed $\alpha 7$-AChRs. Scale bar, $10 \mu \mathrm{m}$.

Figure 7. Confocal double-label micrographs showing extensive overlap of $\alpha 7$ - and $\alpha 3^{*}$-AChR clusters on dissociated ciliary ganglion neurons. $A$, Neuron labeled for $\alpha 7$-AChRs with biotinylated $\alpha$-Bgt followed by FITC-conjugated streptavidin (green). B, Same neuron (Figure legend continues) 
orescence microscopy showed that the membrane structures associated with $\alpha 7$-AChR clusters were highly enriched in bundles of actin filaments, as expected if the structures represented spine clumps (Fig. 6). These structural features, together with the occasional presence of a PSD (see below), strongly suggest they are in fact somatic spines.

Estimates of the total cell surface membrane devoted to somatic spines were generated to calculate the proportion of $\alpha 7$ AChRs located on them. Confocal microscopy indicated that $12.5 \pm 1.6 \%$ (mean $\pm \mathrm{SEM} ; n=16$ neurons) of the surface area on freshly dissociated E15 neurons was occupied by spine clumps (assuming $\alpha 7$-AChR clusters and spine clumps to be coincident). IVEM and tomographic analysis of dissociated neurons indicated that the total surface membrane in spine clumps was 8.4-fold ( \pm 0.8 ; mean $\pm \mathrm{SEM} ; n=8$ regions) more dense per degree of arc than that along nonspiny portions of the soma. Together these numbers produced the unexpected result that spines approximately double the surface area of the neuron.

The mean cell diameter reported above for freshly dissociated E15 neurons would predict a mean total surface area of $\sim 1400$ $\mu \mathrm{m}^{2}$ per cell if the cells were spheres. Capacitance measurements on dissociated E15 neurons produced a mean value of $27.3 \pm 0.6$ pF (Zhang et al., 1994) for cells prepared and generally sizeselected as described here. The capacitance measurements, therefore, indicate an electrically accessible mean total surface area of $\sim 2700 \mu \mathrm{m}^{2}$ for the cells. This is nearly twice that calculated from the mean cell diameter and very close to that predicted for the cells if the spines double the surface area. A limitation of the analysis is that some of the cells extend membrane ruffles along the culture substratum, presumably to enhance attachment (Fig. $6 A$ ). It is not clear whether the membrane ruffles contribute to the capacitance measurement; they are not visible with phasecontrast optics. Even allowing for them in the capacitance measurement, however, suggests that a substantial portion of the spine membrane is likely to be electrically accessible to a recording electrode positioned on the soma.

\section{Codistribution of AChR subtypes}

In addition to $\alpha 7$-AChRs, ciliary ganglion neurons contain heteromeric $\alpha 3^{*}$-AChRs composed of $\alpha 3, \beta 4, \alpha 5$, and occasionally $\beta 2$ subunits that can be distinguished by binding mAb 35 (Vernallis et al., 1993; Conroy and Berg, 1995; Wilson Horch and Sargent, 1995). mAb 35 recognizes the neuronal AChR $\alpha 3$ and $\alpha 5$ gene products but not the $\alpha 4, \alpha 7, \alpha 8, \beta 2$, or $\beta 4$ gene products (Conroy and Berg, 1998). Such receptors were reported previously to be concentrated both at PSDs on the neurons and on the pseudodendrites (Jacob et al., 1984) identified here as somatic spines. Confocal analysis suggested previously that the $\alpha 3^{*}$ AChRs were primarily concentrated in perisynaptic clusters as reported for $\alpha 7$-AChRs (Wilson Horch and Sargent, 1995).

When dissociated ciliary ganglion neurons were double labeled for $\alpha 7$-AChRs with biotinylated $\alpha$-Bgt and for $\alpha 3^{*}$-AChRs with $\mathrm{mAb} 35$, confocal fluorescence microscopy showed considerable overlap in the distribution for the two classes of receptors (Fig. $7 A-C)$. This was most apparent for the larger clusters of $\alpha 7$ - and $\alpha 3^{*}$-AChRs. Small clusters containing only $\alpha 3^{*}$-AChRs or only $\alpha 7$-AChRs, however, were also present. The microclusters of $\alpha 3 *$-AChRs that lack $\alpha 7$-AChRs and ring the larger coclusters have the size and position expected for PSDs on the cells (Jacob and Berg, 1983; Jacob et al., 1984; Wilson Horch and Sargent, 1995). HRP staining of dissociated neurons labeled with mAb 35 confirmed that $\alpha 3^{*}$-AChRs were associated with spines emanating from the cells, as seen above with gold labeling for $\alpha 7$-AChRs (Fig. $7 D$ ). The HRP reaction product was more patchy, however, and less widely distributed than that associated with $\alpha 7$-AChRs.

\section{Proximity of spines and synapses in vivo}

Previous studies have shown $\alpha 7$-AChRs to be undetectable at PSDs on ciliary ganglion neurons (Jacob and Berg, 1983), and yet the receptors contribute importantly to synaptic currents in the neurons (Zhang et al., 1996; Ullian et al., 1997). These results, coupled with the finding reported here that $\alpha 7-\mathrm{AChRs}$ are concentrated on somatic spines, motivated a re-examination of the relationship between spines and presynaptic sites of transmitter release in the ganglion. Tomographic analysis provided an opportunity to obtain a detailed three-dimensional view of the spines in vivo. This served two purposes, one being an assessment of spine proximity to presynaptic specializations such as vesicle-docking sites and the other being an indication of whether the spine configuration observed on dissociated cells was a fair representation of that found in situ when the preganglionic elements remained in place.

E15 ciliary ganglia were thick-sectioned and examined by IVEM. Tomographic reconstruction of the images indicated a complex mat of intertwined and folded somatic spines, best seen by stereoscopic projection (Fig. $8 A$ ). The dimensions and configuration of the spines were similar to those present on dissociated cells. PSDs could be distinguished on somatic membrane in the immediate vicinity of the spine clumps. Individual reconstructed sections generated by the tomographic back projection illustrated the proximity of spines, calyx, and synaptic vesicles (Fig. 8B). When the locations of individual synaptic vesicles were scored and added to the tomographic reconstruction, it became clear that the vesicles were concentrated not only over the PSDs but also over the folded spines even though no PSDs were apparent on the spines in the field of view (Fig. $8 B, C$ ). Adding the calyx profile to the image illustrated how it engulfed the folded spines and extended small projections among the spines (Fig. 8C).

Conventional EM on thin sections provided additional detail. Spines were often closely packed to form a clump overlaid on the cell soma but were interdigitated with calyx projections filled with synaptic vesicles (Fig. 9A). PSDs could be found both on the soma membrane close to the base of the spines and on the spines themselves in some cases (Fig. 9A,B). Synaptic vesicles were packed close to the calyx membrane ensheathing the spines, often being in such proximity as to suggest that some of the vesicles may have been docked at release sites (Fig. 9B,C). Occasionally the spines projected deep into the calyx where they were surrounded with synaptic vesicles. In some instances a spine was caught in cross section emerging from the soma near a PSD in the same

\section{$\longleftarrow$}

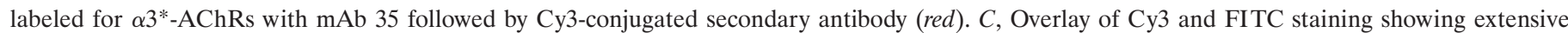

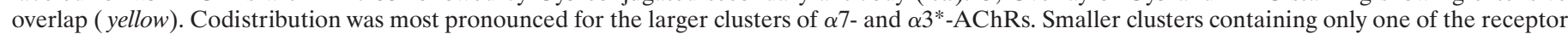

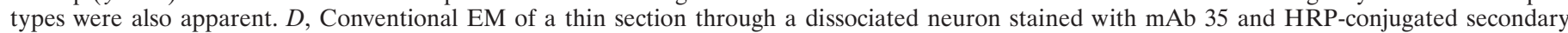

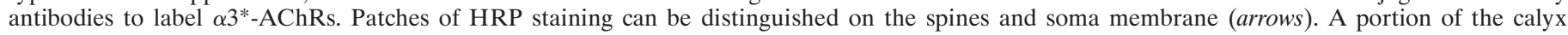
containing synaptic vesicles remains attached to the cell in this case. Scale bars: $A-C, 5 \mu \mathrm{m} ; D, 500 \mathrm{~nm}$. 

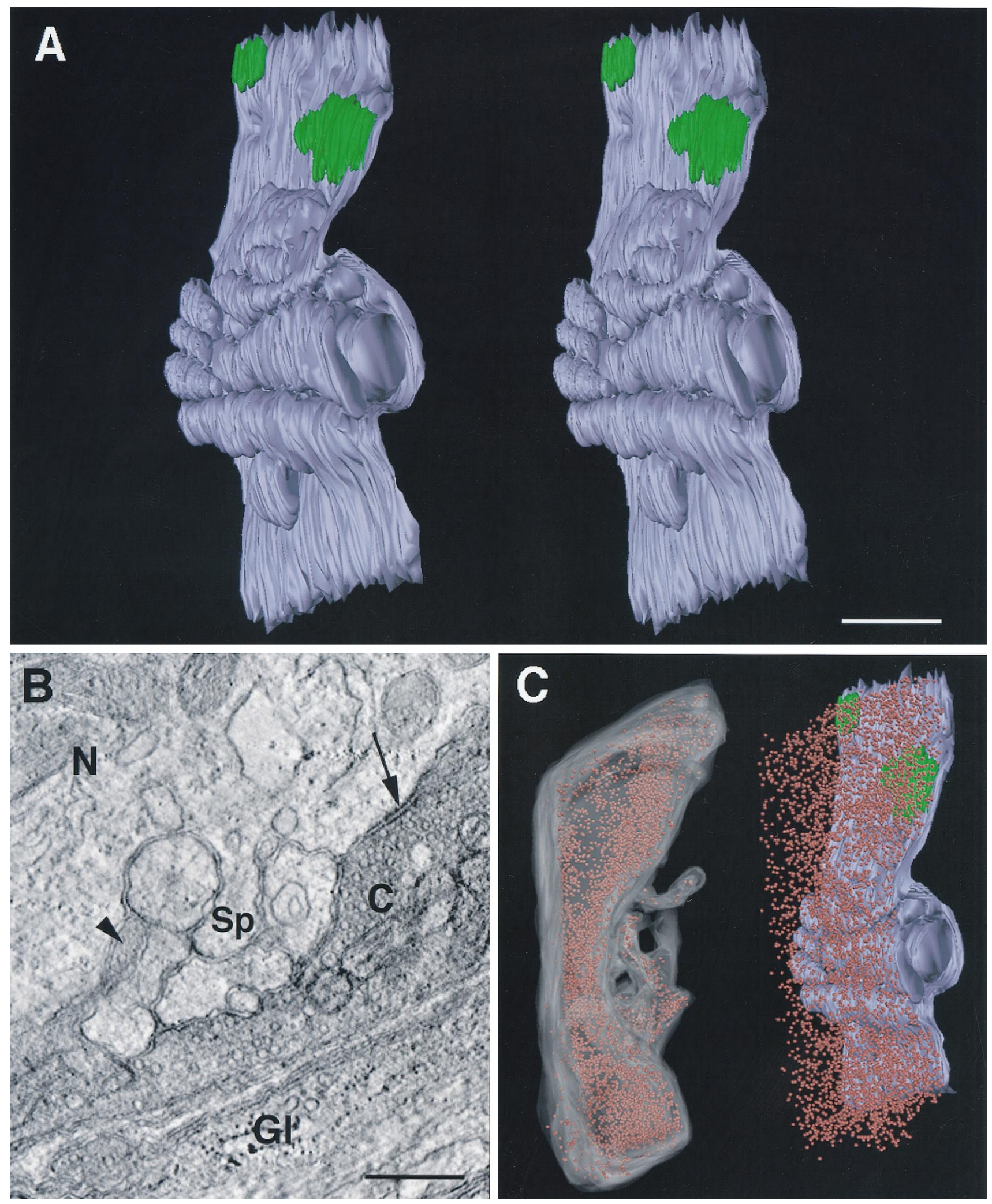

Figure 8. Tomographic reconstruction of ciliary ganglion neuron surface in situ showing complexes of matted spines, overlaid synaptic vesicles, and nearby PSDs. $A$, Stereo pair of images showing a three-dimensional view of a membrane patch containing matted spines on a neuron in situ. Note the locations of nearby PSDs ( green). B, One of many computer-generated slices through the reconstructed volume. A vesicle-filled calyx extension underlies the mat of spines (arrowhead). A synapse adjacent to the spines is indicated by the arrow. $C$, Same image as in $A$ (75\% scale) with overlaid synaptic vesicles (red) on the right and the accompanying calyx structure (gray) on the left containing the same vesicles and rotated $70^{\circ}$ out from the plane of the neuron surface. For clarity, only a representative $20 \%$ of the vesicles are indicated. The calyx image shows thin projections that extend into the mat of spines; synaptic vesicles are densely packed over the spines even though PSDs are located only at the perimeter. $C$, Calyx; $G l$, glial cell; $N$, neuronal soma; Sp, spine. Scale bars, $500 \mathrm{~nm}$. 

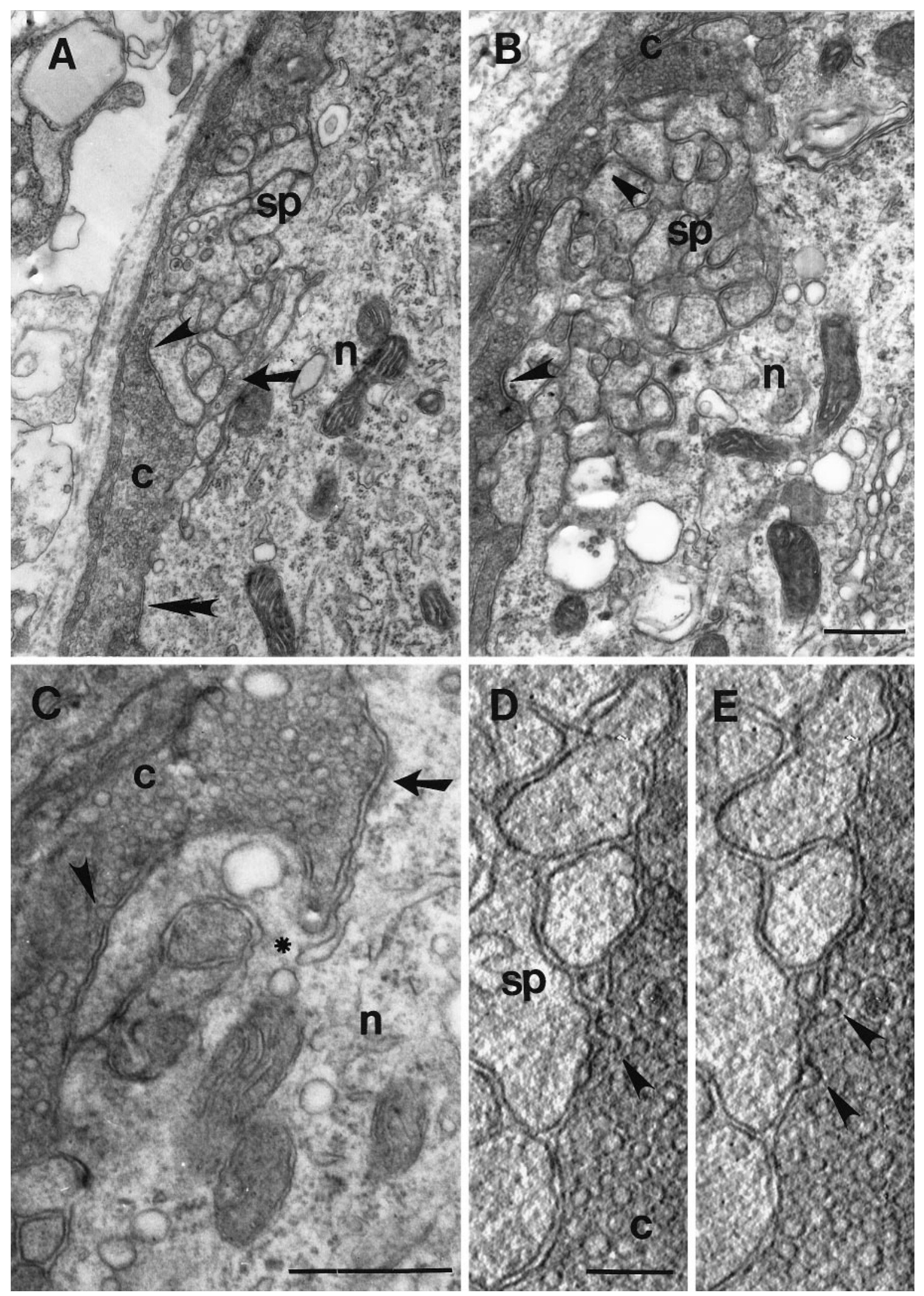

Figure 9. The relationship of calyx membrane, spines, synaptic vesicles, and PSDs as shown by conventional electron micrographs of the intact ganglion in thin sections $(A-C)$ and by high-magnification tomographic-reconstructed views from thick sections $(D, E)$. $A$, A mat of folded spines invested with a calyx projection (arrow) filled with synaptic vesicles. A PSD can be distinguished both on the soma membrane near the spines (double arrowhead) and on a spine itself (arrowhead). B, A mat of folded spines overlaid with calyx densely packed with synaptic vesicles. Two PSDs can be distinguished on the spines (arrowheads), and synaptic vesicles are tightly packed near the spine membrane in other regions as well that lack (Figure legend continues) 
field of view; synaptic vesicles could be seen tightly packed along its length (Fig. $9 C$ ). In the example shown, an $\Omega$ profile can also be distinguished in the calyx membrane, possibly representing a synaptic vesicle caught in midexocytosis onto the spine surface (Fig. 9C). Higher magnification tomographic sections of other regions provided additional examples of $\Omega$ profiles opposed to spines even though no PSD was present in the entire volume sampled (Fig. 9D,E). The absence of clathrin coats suggested that the $\Omega$ structures represented exocytotic events rather than endocytotic ones. Clathrin-coated pits were occasionally observed both on calyx and spine membrane, confirming that the structures could be distinguished when present.

\section{DISCUSSION}

The principal findings reported here are that $\alpha 7$-AChRs are concentrated on ciliary ganglion somatic spines. The spines are arranged in clumps on the ciliary neuron surface and are folded into tightly matted arrays. The matted spines effectively double the total surface area of the cell and position much of it close to presynaptic calyx membrane. Although $\alpha 7$-AChRs may be excluded from PSDs on the neurons, the receptors are in close proximity to numerous potential sites of transmitter release by virtue of their distribution along spines. The elaborate spine configuration implies a specialized synaptic function, and the accompanying distribution of $\alpha 7$-AChRs indicates that neurons have specific mechanisms for targeting $\alpha 7$-AChRs to desired locations.

Spine-like projections emanating from neuron cell bodies have been described in several kinds of autonomic ganglia (Piezzi and Rodriquez-Echandia, 1968; Watanabe, 1971; Smolen, 1988; Robertson and Jackson, 1996). Identification of the projections as somatic spines in the present experiments depended on several criteria. Chief among these were their dimensions, their cytoskeletal composition (presence of actin filaments and absence of microtubules), and their proximity to presynaptic elements. Usually another defining feature of both dendritic and somatic spines is the presence of a PSD (Harris and Kater, 1994). Analysis of ciliary ganglion sections revealed PSDs on some somatic spines but not on others. It is unclear whether this represents a structural heterogeneity among the spines or whether PSDs were often missed because the spines rarely were captured in their entirety within the section being examined. A previous report described rare somatic spines with opposing PSDs on both sides of the spine neck on ciliary ganglion neurons; the structures did not appear until 2 weeks after hatching and were found in only a few of many ganglia examined (Takahashi, 1967). Serial-section EM analysis of ciliary neurons in situ may be necessary to define the full extent of spines and to quantify PSDs on them.

The immunogold labeling with biotinylated $\alpha$-Bgt permitted a quantitative demonstration for the first time that $\alpha 7$-AChRs are preferentially concentrated on somatic spines rather than being randomly distributed throughout the surface membrane. Because spines contribute approximately one-half of the total surface area of E15 ciliary neurons and contain an order of magnitude greater density of $\alpha$-Bgt-binding sites than does the soma membrane, they account for $\sim 90 \%$ of the total $\alpha 7$-AChRs on the neurons. The few $\alpha$-Bgt-binding sites in ciliary ganglia not associated with $\alpha 7$ protein $(\leq 5 \%)$ are unlikely to have contributed significantly because of their scarcity (Pugh et al., 1995) and because anti- $\alpha 7$ antibodies and $\alpha$-Bgt produced the same labeling patterns. If one-half of the $\sim 20$ fmol of $\alpha$-Bgt-binding sites in E15 ciliary ganglia (Chiappinelli and Giacobini, 1978; Corriveau and Berg, 1994) are on the estimated 1600 ciliary neurons present (Landmesser and Pilar, 1974), the $1400 \mu \mathrm{m}^{2}$ calculated here for the aggregate spine surface per E15 neuron should have a mean binding-site density of $\sim 2 \times 10^{3}$ per $\mu \mathrm{m}^{2}$. This value is intermediate between the $\sim 0.6 \times 10^{3}$ and $5 \times 10^{3}$ neuronal bungarotoxin-binding sites per $\mu \mathrm{m}^{2}$ estimated by EM autoradiography for AChRs (non- $\alpha 7$ ) at PSDs on chick ciliary ganglion neurons in situ and on rat sympathetic neurons in culture, respectively (Loring and Zigmond et al., 1987; Loring et al., 1988). If $\alpha 7$-AChRs have one to two $\alpha$-Bgt-binding sites (Schoepfer et al., 1990; Chen and Patrick, 1997; but see Palma et al., 1996), the inferred receptor density would be approximately an order of magnitude below the $2 \times 10^{4} \mathrm{AChRs}$ per $\mu \mathrm{m}^{2}$ at the mammalian neuromuscular junction (Fertuck and Salpeter, 1976). Because $\alpha 7$-AChRs are widely expressed in the nervous system, it will be important to determine whether they are commonly associated with spines.

The HRP-labeling studies with mAb 35 indicate that $\alpha 3^{*}$ AChRs are distributed along the spines as well. The receptors are less abundant than are $\alpha 7$-AChRs (Chiappinelli and Giacobini, 1978; Smith et al., 1985; Corriveau and Berg, 1994) but may be intermingled with them. Alternatively, they may be segregated to different regions on the spines or to different spines within a clump. The results corroborate and extend those obtained with conventional EM and HRP labeling of neurons in situ (Jacob and Berg, 1983; Jacob et al., 1984). Those results also showed, however, as did EM autoradiographic analysis (Loring and Zigmond, 1987), that a portion of the $\alpha 3^{*}$-AChRs is uniquely concentrated at PSDs. Such receptors may comprise a small fraction of the total $\alpha 3^{*}$-AChRs and appear in confocal microscopy as the microclusters of mAb 35-binding sites seen near but not overlapping with the larger $\alpha 7$ - and $\alpha 3^{*}$-AChR coclusters both here on dissociated cells and previously in situ (Wilson Horch and Sargent, 1995).

How do $\alpha 7$-AChRs become synaptically activated if they are excluded from PSDs? The present results suggest two kinds of mechanisms. One arises from the proximity of spines to PSDs. Transmitter released onto PSDs could spread rapidly by diff usion to adjacent spine surfaces (Clements, 1996) and produce the $\sim 1$ msec rise times for synaptic currents caused by $\alpha 7$-AChRs (Zhang et al., 1996; Ullian et al., 1997). A different possibility is that vesicular release of transmitter may occur directly onto spine membrane even without PSDs. Such might be the purpose of having both large amounts of spine surface and vast numbers of

\section{$\longleftarrow$}

PSDs. $C$, A spine in longitudinal section showing the base (asterisk) with a PSD on the adjacent soma membrane (arrow) and synaptic vesicles tightly lining the calyx membrane along the spine as if some may have been docked for release. An $\Omega$ profile (arrowhead) can be distinguished in the calyx membrane as if a vesicle had been trapped in midexocytosis onto the spine surface. $D, E$, Two high-magnification tomographically reconstructed images $\sim 40 \mathrm{~nm}$ apart from the same thick section. Multiple spines are seen in cross section (one of which is labeled) stacked up along the vesicle-containing calyx. Several $\Omega$ profiles are indicated (arrowheads). The absence of clathrin coats in these cases supports the interpretation that they represent exocytotic rather than endocytotic events. Examination of serial reconstructed images confirmed the absence of PSDs from the entire 1- $\mu \mathrm{m}$-thick volume sampled. $c$, Calyx; $n$, neuron; $s p$, spine. Scale bars: $A, B, 500 \mathrm{~nm} ; C, 500 \mathrm{~nm} ; D, E, 200 \mathrm{~nm}$. 
synaptic vesicles packed tightly along the calyx membrane juxtaposed to spines. The occasional $\Omega$ membrane profiles seen at such locations could represent examples of vesicular release; they lack the clathrin coats expected for endocytotic events. The multiple spines and the abundance of synaptic vesicles along them could ensure reliable high-frequency transmission even if release occurred as a low-probability event per unit area of membrane. This mode of synaptic transmission may be more widespread in the nervous system than previously imagined.

Previous confocal microscopic analysis using immunofluorescence suggested that synaptic vesicle protein did not overlap in distribution with $\alpha 7$-AChR clusters on ciliary ganglion neurons (Wilson Horch and Sargent, 1995). This led to the suggestion that the receptor clusters were perisynaptic. Confocal imaging of dissociated neurons displayed the same kinds of $\alpha 7$-AChR clusters in the present experiments, but double labeling with phalloidin for bundled actin and with biotinylated $\alpha$-Bgt for $\alpha 7$-AChRs indicated the clusters were coextensive with somatic spine clumps. (The spines presumably survived the dissociation procedure because they were folded and packed on the cell surface; the folding appeared only slightly less compact than on cells in vivo.) Immunogold labeling of dissociated cells showed that most, if not all, of the spines were heavily endowed with $\alpha 7$-AChRs, as indicated above. The EM analysis performed here on sectioned ganglia indicated a close alignment between synaptic vesicles in the calyx and juxtaposed spines on the cell body. As a result, $\alpha 7$-AChRs must be in close apposition to synaptic vesicles. It is not clear why an association of vesicles and $\alpha 7$-AChRs was not detected previously; possibly the high density of vesicles throughout the calyx core necessitated an attenuation of the fluorescence monitoring such that vesicles positioned peripherally near spines were obscured.

Nearly all of the current generated by $\alpha 7$-AChRs on the spines should reach the soma. This follows from the observation that the spines are only a few micrometers in length and have a diameter of $\sim 0.2 \mu \mathrm{m}$ that predicts a space constant in excess of $200 \mu \mathrm{m}$ (Plonsey and Barr, 1989). The EM images revealed no physical restrictions at the base of the spines that might impede current flow. Many of the $\alpha 7$-AChRs are probably exposed to transmitter during each synaptic trial because of the anatomical features described above and because of studies with an esterase inhibitor suggesting that the $\alpha 7-\mathrm{AChR}$ synaptic response is limited by receptor desensitization rather than by transmitter availability during a stimulus (Zhang et al., 1996). Given these considerations, it is surprising that estimates of $\alpha 7$-AChR single-channel properties suggested that only a few percent of the $\alpha 7$-AChRs might be sufficient to account for the synaptic currents observed (Ullian et al., 1997). If the assumptions about $\alpha 7$-AChR properties were correct, the results imply that many of the receptors either may not be functionally available during a given trial because of some regulatory constraint or may quickly desensitize during initial exposure to agonist.

What is the function of somatic spines, and why are $\alpha 7$-AChRs concentrated on them? One reason may be that the enlarged surface area contributed by spines increases the safety factor for reliable transmission in an economical manner. A second reason is that spines may compartmentalize some consequence of synaptic signaling (Koch and Zador, 1993). A prime candidate is calcium influx. The relative calcium permeability of $\alpha 7$-AChRs is as high as that of NMDA receptors (Bertrand et al., 1993; Seguela et al., 1993). Given the high-frequency firing possible in the ciliary ganglion (Dryer, 1994), substantial calcium influx may occur through $\alpha 7$-AChRs. Localizing the receptors on spines could sequester the calcium and protect the cell body from activitydriven cytotoxicity (Harris and Kater, 1994). Sequestering calcium in spines may also enable higher levels to be sustained for long-term regulatory effects.

\section{REFERENCES}

Anand R, Peng X, Lindstrom J (1993) Homomeric and native $\alpha 7$ acetylcholine receptors exhibit remarkably similar but non-identical pharmacological properties, suggesting that the native receptor is a heteromeric protein complex. FEBS Lett 327:241-246.

Bertrand D, Galzi JL, Devillers-Thiery A, Bertrand S, Changeux JP (1993) Mutations at two distinct sites within the channel domain M2 alter calcium permeability of neuronal $\alpha 7$ nicotinic receptor. Proc Natl Acad Sci USA 90:6971-6975.

Chen D, Patrick JW (1997) The $\alpha$-bungarotoxin-binding nicotinic acetylcholine receptor from rat brain contains only the $\alpha 7$ subunit. J Biol Chem 272:24024-24029.

Chiappinelli VA, Giacobini E (1978) Time course of appearance of $\alpha$-bungarotoxin binding sites during development of chick ciliary ganglion and iris. Neurochem Res 3:465-478.

Clements JD (1996) Transmitter timecourse in the synaptic cleft: its role in central synaptic function. Trends Neurosci 19:163-171.

Coggan JS, Paysan J, Conroy WG, Berg DK (1997) Direct recording of nicotinic responses in presynaptic nerve terminals. J Neurosci 17:5798-5806.

Conroy WG, Berg DK (1995) Neurons can maintain multiple classes of nicotinic acetylcholine receptors distinguished by different subunit compositions. J Biol Chem 270:4424-4431.

Conroy WG, Berg DK (1998) Nicotinic receptor subtypes in the developing chick brain: appearance of a species containing the $\alpha 4, \beta 2$, and $\alpha 5$ gene products. Mol Pharmacol 53:392-401.

Corriveau RA, Berg DK (1993) Co-expression of multiple acetylcholine receptor genes in neurons: quantification of transcripts during development. J Neurosci 13:2662-2671.

Corriveau RA, Berg DK (1994) Neurons in culture maintain acetylcholine receptor levels with far fewer transcripts than in vivo. J Neurobiol 25:1579-1592.

Couturier S, Bertrand D, Matter J-M, Hernandez M-C, Bertrand S, Millar N, Valera S, Barkas T, Ballivet M (1990) A neuronal nicotinic acetylcholine receptor subunit $(\alpha 7)$ is developmentally regulated and forms a homo-oligomeric channel blocked by $\alpha$-Btx. Neuron 5:847-856.

Dryer S (1994) Functional development of the parasympathetic neurons of the avian ciliary ganglion: a classic model system for the study of neuronal differentiation and development. Prog Neurobiol 43:281-322.

Fertuck HC, Salpeter MM (1976) Quantitation of junctional and extrajunctional acetylcholine receptors by electron microscope autoradiography after I-125- $\alpha$-bungarotoxin binding at mouse neuromuscular junctions. J Cell Biol 69:144-158.

Gray R, Rajan AS, Radcliffe KA, Yakehiro M, Dani JA (1996) Hippocampal synaptic transmission enhanced by low concentrations of nicotine. Nature 383:713-716.

Guo J-Z, Tredway TL, Chiappinelli VA (1998) Glutamate and GABA release are enhanced by different subtypes of presynaptic nicotinic receptors in the lateral geniculate nucleus. J Neurosci 18:1963-1969.

Harris KM, Kater SB (1994) Dendritic spines: cellular specializations imparting both stability and flexibility to synaptic function. Annu Rev Neurosci 17:341-371.

Hess A (1965) Developmental changes in the structure of the synapse on the myelinated cell bodies of the chicken ciliary ganglion. J Cell Biol 25:1-19.

Hessler D, Young SJ, Carragher BO, Martone M, Lamont S, Whittaker M, Milligan RA, Masliah E, Hinshaw JE, Ellisman MH (1992) Programs for visualization in 3-dimensional microscopy. NeuroImage 1:55-67.

Jacob MH, Berg DK (1983) The ultrastructural localization of $\alpha$-bungarotoxin binding sites in relation to synapses on chick ciliary ganglion neurons. J Neurosci 3:260-271.

Jacob MH, Berg DK, Lindstrom JM (1984) Shared antigenic determinant between the Electrophorus acetylcholine receptor and a synaptic component on chicken ciliary ganglion neurons. Proc Natl Acad Sci USA 81:3223-3227.

Koch C, Zador A (1993) The function of dendritic spines: devices sub- 
serving biochemical rather than electrical compartmentalization. J Neurosci 13:413-422.

Landmesser L, Pilar G (1972) The onset and development of transmission in the chick ciliary ganglion. J Physiol (Lond) 222:691-713.

Landmesser L, Pilar G (1974) Synapse formation during embryogenesis on ganglion cells lacking a periphery. J Physiol (Lond) 241:715-736.

Li X, Rainnie DG, McCarley RW, Greene RW (1998) Presynaptic nicotinic receptors facilitate monoaminergic transmission. J Neurosci 18:1904-1912.

Loring RH, Zigmond RE (1987) Ultrastructural distribution of ${ }^{125} \mathrm{I}$ toxin $\mathrm{F}$ binding sites on chick ciliary neurons: synaptic localization of a toxin that blocks ganglionic nicotinic receptors. J Neurosci 7:2153-2162.

Loring RH, Dahm LM, Zigmond RE (1985) Localization of $\alpha$-bungarotoxin binding sites in the ciliary ganglion of the embryonic chick: an autoradiographic study at the light and electron microscopic level. Neuroscience 14:645-660.

Loring RH, Sah DWY, Landis SC, Zigmond RE (1988) The ultrastructural distribution of putative nicotinic receptors on cultured neurons from the rat superior cervical ganglion. Neuroscience 24:1071-1080.

McGehee D, Heath M, Gelber S, Role LW (1995) Nicotine enhancement of fast excitatory synaptic transmission in CNS by presynaptic receptors. Science 269:1692-1697.

Palma E, Bertrand S, Binzoni T, Bertrand D (1996) Neuronal nicotinic $\alpha 7$ receptor expressed in Xenopus oocytes presents five putative binding sites for methyllycaconitine. J Physiol (Lond) 491:151-161.

Perkins GA, Renken CW, Song JY, Frey TG, Young SJ, Lanont S, Martone ME, Lindsey S, Ellisman MH (1997) Electron tomography of large multicomponent biological structures.

Piezzi RS, Rodriguez-Echandia EL (1968) Studies on the pararenal ganglion of the Bufo arenarum Hensel. I. Its normal fine structure and histochemical characteristics. Z Zellforsch Mikrosk Anat 88:180-186.

Pilar G, Tuttle JB (1982) A simple neuronal system with a range of uses: the avian ciliary ganglion. In: Progress in cholinergic biology (Hanin I, Goldberg AM, eds), pp 213-247. New York: Raven.

Plonsey R, Barr R (1989) Bioelectricity. New York: Plenum.

Pugh PC, Corriveau RA, Conroy WG, Berg DK (1995) A novel subpopulation of neuronal acetylcholine receptors among those binding $\alpha$-bungarotoxin. Mol Pharmacol 47:717-725.

Robertson GN, Jackson PC (1996) Axosomatic synapses of the rat ciliary ganglion. Synapse 22:269-280.

Schoepfer R, Conroy WG, Whiting P, Gore M, Lindstrom J (1990) Brain $\alpha$-bungarotoxin binding protein cDNAs and mAbs reveal subtypes of this branch of the ligand-gated ion channel gene superfamily. Neuron $5: 35-48$.

Seguela P, Wadiche J, Dineley-Miller K, Dani JA, Patrick JW (1993) Molecular cloning, functional properties, and distribution of rat brain $\alpha 7$ : a nicotinic cation channel highly permeable to calcium. J Neurosci 13:596-604.

Smith MA, Margiotta JF, Berg DK (1983) Differential regulation of acetylcholine sensitivity and $\alpha$-bungarotoxin-binding sites on ciliary ganglion neurons in cell culture. J Neurosci 3:2395-2402.

Smith MA, Stollberg J, Lindstrom JM, Berg DK (1985) Characterization of a component in chick ciliary ganglia that cross-reacts with monoclonal antibodies to muscle and electric organ acetylcholine receptor. J Neurosci 5:2726-2731.

Smolen A (1988) Morphology of synapses in the autonomic nervous system. J Electron Microsc Tech 10:187-204.

Soto GE, Young SJ, Martone ME, Deerinck TJ, Lamont S, Carragher BO, Hama K, Ellisman MH (1994) Serial section electron tomography: a method for three-dimensional reconstruction of large structures. NeuroImage 1:230-243.

Szentagothai J (1964) The structure of the autonomic interneuronal synapse. Acta Neurovegetativa 26:338-359.

Takahashi K (1967) Special somatic spine synapses in the ciliary ganglion of the chick. Z Zellforsch Mikrosk Anat 83:70-75.

Ullian EM, McIntosh JM, Sargent PB (1997) Rapid synaptic transmission in the avian CG is mediated by two distinct classes of nicotinic receptors. J Neurosci 17:7210-7219.

Vernallis AB, Conroy WG, Berg DK (1993) Neurons assemble acetylcholine receptors with as many as three kinds of subunits while maintaining subunit segregation among receptor subtypes. Neuron 10:451-464.

Watanabe H (1971) Adrenergic nerve elements in the hypogastric ganglion of the guinea pig. Am J Anat 130:305-330.

Wilson Horch HL, Sargent PB (1995) Perisynaptic surface distribution of multiple classes of nicotinic acetylcholine receptors on neurons in the chicken ciliary ganglion. J Neurosci 15:7778-7795.

Zhang Z-w, Vijayaraghavan S, Berg DK (1994) Neuronal acetylcholine receptors that bind $\alpha$-bungarotoxin with high affinity function as ligandgated ion channels. Neuron 12:167-177.

Zhang Z-w, Coggan JS, Berg DK (1996) Synaptic currents generated by neuronal acetylcholine receptors sensitive to $\alpha$-bungarotoxin. Neuron 17:1231-1240. 